\title{
Impact of Washing Followed by Calcination on the Quality of Bouchane Phosphate of Morocco
}

\author{
El Mokhtar El Ouardi ${ }^{1,2^{*}}$, Abdellah Zeroual ${ }^{3}$, Keltoum Khallouq $^{4}$, Salah Darfi ${ }^{5}$, Abdesselam Jedaa ${ }^{1}$ \\ ${ }^{1}$ Laboratory of Fundamental and Applied Physics, Department of Physics, Polydisciplinary Faculty of Safi, Cadi Ayyad \\ University, Marrakesh 40000, Morocco \\ ${ }^{2}$ Complex System and Interactions Team, Faculty of Applied Sciences - Ait melloul, Ibn Zohr University, Agadir 80000, \\ Morocco \\ ${ }^{3}$ Molecular Modeling and Spectroscopy Research Team, Faculty of Science, Chouaïb Doukkali University, P.O. Box 20, \\ 24000 El Jadida, Morocco \\ ${ }^{4}$ Laboratory of Condensed Matter Physics and Nanomaterials for Renewable Energy, University Ibn Zohr, Agadir 80000, \\ Morocco \\ ${ }^{5}$ Measurement and Control Instrumentation Laboratory, Faculty of Sciences, Chouaib Doukkali University, El Jadida 24000 , \\ Morocco
}

Corresponding Author Email: e.elouardi@uiz.ac.ma

https://doi.org/10.18280/ijdne.150413

Received: 10 May 2020

Accepted: 19 June 2020

\section{Keywords:}

enrichment, Bouchane phosphate, calcination, washing, quality

\begin{abstract}
The aim of the present work is to compare two enrichment processes of the Bouchane phosphate. The first one is the usual calcination of the raw phosphate and the second is the calcination of the washed raw phosphate. We investigated the variation of some physicochemical properties, namely the specific surface, the volume mass and the mass percentage of the main constituents of the calcination of phosphates such as Organic carbon $\left(\mathrm{C}_{\text {org }}\right)$, Carbon dioxide $\left(\mathrm{CO}_{2}\right)$, Phosphorus pentoxide $\left(\mathrm{P}_{2} \mathrm{O}_{5}\right)$, and Lime $(\mathrm{CaO})$, during these processes as a function of time and temperature. For this purpose, different analysis techniques were used such as the granulometric analysis, the quantitative analysis by volumetric method and by inductively coupled plasma atomic emission spectroscopy (ICP-AES), the mineralogical characterization by X-ray diffraction and differential thermic analysis coupled with thermogravimetric analysis. We concluded that a pre-washing a raw phosphate is critical to improving the quality of phosphates. A calcination at $800^{\circ} \mathrm{C}$ for 30 minutes reduces mass percentages of organic carbon by $88.60 \%$ and $91.43 \%$, carbon dioxide by $53.00 \%$ and $54.54 \%$, while the masses of $\mathrm{P}_{2} \mathrm{O}_{5}$ is increased by $9.15 \%$ and $10.46 \%$, for the calcined raw phosphate and the raw phosphate washed and then calcined, respectively. It follows that the second procedure favors the reduction of energy consumption, which, in turns, is subsequently beneficial to the environment since it decreases the emission of $\mathrm{CO}_{2}$ by improving the quality through increasing the chemical reactivity and solubility.
\end{abstract}

\section{INTRODUCTION}

Phosphate is used as mineral fertilizers in agriculture, and nowadays, its consumption shows an increasing rate worldwide. Most of the world's phosphate deposits are of sedimentary origin. These deposits usually have very varied physicochemical and crystallographic properties, which are related to the geological conditions leading to an alteration of mineral depositions [1]. A group of apatite combined with, other minerals and impurities, mainly composes the phosphates deposits. Fluorapatite-hydroxylated and/or francolites poles mostly represent these sediments. They contain impurities sometimes with high concentrations, which would enormously affect their quality. The francolites are different from fluorapatite by their chemical compositions; they offer a larger specific surface and therefore a higher solubility and chemical reactivity [2-4]. Among the minerals and impurities found: the organic matter, quartz, clay minerals, carbonates, radioactive elements, metal oxides and several other kinds of impurities, with different combinations and concentrations [5]. These parasites are decisive when it comes the legislation and assessment of natural phosphates. They have adverse effects manifested not only when direct use is implemented, but also during the various stages of transformation into phosphate derivatives [6]. Therefore, impurities have no economic interest. The enrichment of phosphates is, accordingly, an important step to overcome a large part of these disadvantages.

To meet the use standard of phosphate, several methods have been used for the enrichment, depending on the type of the ore, associated gangue minerals and the impurity concentrations [7-11]. These methods include gravity separation [12-15], magnetic separation [12], electrostatic separation [13], size reduction, screening [14], attrition, purification, classification, separation of heavy metals $[15,16]$, calcination [16], acid leaching [17, 18], direct flotation [19], [20], reverse flotation [21] and the combination of several of these methods. 
The Enrichment by calcination is one of the best-known methods. It can be used to treat carbonate sedimentary phosphate ores [22]. More than $10 \%$ of global phosphate sales are based on this technique [23]. Calcination involves thermal decomposition of carbonates and combustion of organic materials. However, it has several disadvantages [13], such as high energy costs [22], a low reactivity of the finished products and high costs of calcination factories [10].

According to their physicochemical and mineralogical characteristics, the Bouchane phosphate deposit is a francolite type containing apatite as main mineral and different assortment of accessory minerals like fluorides, carbonates (calcites, dolomite), quartz, silicates and metal oxides as well as organic matter [24]. Although these deposits are characterized by an average total $\mathrm{P}_{2} \mathrm{O}_{5}$ content that exceeds $29 \%$ on average, it needs optimal treatments are needed to improve phosphate quality.

The challenge posed by this work is the comparative study between of calcined raw phosphate (CRP) and washed raw phosphate prior to calcination (WRPC) to explain the impact of a prewash followed by calcination on the physico-chemical properties and on the quality of phosphate. For this; we carried out a characterization study of the ore, as well as the study of the thermal behavior of the main constituents of control and of the mineral matrix before and after the treatment.

\section{CHARACTERIZATION \\ OF \\ BOUCHANE PHOSPHATE}

The Bouchane deposit is located $40 \mathrm{~km}$ east of Youssoufia city, which is the western part of the Gantour phosphate field. It has significant reserves of phosphates and it is the focus of particular attention. The phosphate in this area has interesting granulometric and chemical properties such as a small quantity of organic matter and carbonates as well as the mass percentage of the desired particle size distribution is important.

\subsection{Sample preparation}

We have taken a series of phosphate samples from this deposit. The samples have been classified in the laboratory and brought into contact with open air in inert bags before being subjected to wash and heat treatments, and then measurements and analysis (qualitative and quantitative).

\subsection{Physicochemical characterization of raw phosphate in the zone studied}

\subsubsection{Dimensional rankings}

The granulometric distribution of the phosphate was realized by dry sieving. We have used a series of nylon cloth sieves of a mesh round holes in geometrical progressions (Table 1).

The results gathered from Table 1 show that the greater part (about $80 \%$ ) exists between 125 and $800 \mu \mathrm{m}$. This has an added value when it comes to free mechanical processing.

In the laboratory, a quantity of raw phosphate has been submitted to mechanical treatment using a grinder hammer. We have proceeded successive operations based on refusals of the mesh of $800 \mu \mathrm{m}$ and sieving the fine part lower than 40 $\mu \mathrm{m}$. Half of the quantity is subjected to washing with water then dried. Subsequently, we performed a sieving on the two parts which we will use in all the physicochemical characterizations. The results of the classification are indicated in Table 2.

We note that the granulometric between 160 and $500 \mu \mathrm{m}$ (about $70.5 \%$ for RP and $72 \%$ for WRP) is the richest part in phosphorus [25-28].

Table 1. Dimensional classifications by sieving before the sample's grinding of the raw phosphate

\begin{tabular}{ccc}
\hline $\begin{array}{c}\text { Openings of } \\
\text { sieve }(\boldsymbol{\mu m})\end{array}$ & $\begin{array}{c}\text { Cumulative yield } \\
\text { of sieved mass }(\%)\end{array}$ & $\begin{array}{c}\text { Cumulative yield } \\
\text { of refusals }(\boldsymbol{\%})\end{array}$ \\
\hline $40<$ & 1.12 & 98.88 \\
$40-80$ & 3.02 & 96.98 \\
$80-125$ & 5.29 & 94.71 \\
$125-160$ & 13.04 & 86.96 \\
$160-200$ & 20.92 & 79.08 \\
$200-250$ & 31.78 & 68.22 \\
$250-315$ & 42.44 & 57.56 \\
$315-500$ & 58.38 & 41.62 \\
$500-800$ & 85.21 & 14.79 \\
$800-1000$ & 92.39 & 7.61 \\
$1000-1250$ & 94 & 6 \\
$1250-2000$ & 96.68 & 3.32 \\
\hline
\end{tabular}

Table 2. Dimensional classifications by sieving after grinding for samples raw phosphate (RP) and the washed raw phosphate (WRP)

\begin{tabular}{ccccc}
\hline $\begin{array}{c}\text { Openings } \\
\text { of sieve }\end{array}$ & \multicolumn{2}{c}{$\begin{array}{c}\text { Cumulative yield } \\
\text { of sieved mass }(\boldsymbol{\%})\end{array}$} & \multicolumn{2}{c}{$\begin{array}{c}\text { Cumulative yield } \\
\text { of refusals }(\%)\end{array}$} \\
\cline { 2 - 5 }$(\boldsymbol{\mu m})$ & $\mathrm{RP}$ & WRP & RP & WRP \\
$40<$ & 0.0 & 0.0 & 100 & 100 \\
$40-80$ & 3.0 & 2.6 & 97.0 & 97.4 \\
$80-125$ & 6.3 & 6.0 & 93.7 & 94.0 \\
$125-160$ & 13.94 & 14.2 & 86.06 & 85.8 \\
$160-200$ & 23.19 & 24.1 & 76.81 & 75.9 \\
$200-250$ & 35.69 & 36.3 & 64.31 & 63.7 \\
$250-315$ & 53.94 & 55.4 & 46.06 & 44.6 \\
$315-500$ & 85.4 & 86.2 & 14.6 & 13.8 \\
$500-800$ & 100 & 100 & 0.0 & 0.0 \\
\hline
\end{tabular}

\subsubsection{Quantitative chemical analysis}

The volumetric method is commonly used to frequently control the main components of control $\left(\mathrm{C}_{\text {org }}, \mathrm{CO}_{2}, \mathrm{P}_{2} \mathrm{O}_{5}\right.$ and $\mathrm{CaO})$. The results of RP and WRP analysis are indicated in Table 3 .

Table 3. Medium chemical compositions of the phosphates samples RP and WRP

\begin{tabular}{ccc}
\hline Elements & \% mass of RP & \% mass of WRP \\
\hline $\mathrm{P}_{2} \mathrm{O}_{5}$ & $30.90 \pm 0.08$ & $31.65 \pm 0.08$ \\
$\mathrm{CaO}$ & $49.60 \pm 0.18$ & $50.72 \pm 0.19$ \\
$\mathrm{CO}_{2}$ & $6.60 \pm 0.08$ & $6.00 \pm 0.08$ \\
$\mathrm{C}_{\text {org }}$ & $1.40 \pm 0.02$ & $1.34 \pm 0.02$ \\
$\mathrm{H}_{2} \mathrm{O}$ & $4.85 \pm 0.01$ & $4.20 \pm 0.01$ \\
Others & $6.65 \pm 0.52$ & $6.09 \pm 0.45$ \\
$\mathrm{CaO} / \mathrm{P}_{2} \mathrm{O}_{5}$ & 1.6 & 1.6 \\
\hline
\end{tabular}

For WRP, an increase in mass percentage of $\mathrm{P}_{2} \mathrm{O}_{5}$ and the ratio of $\mathrm{CaO} / \mathrm{P}_{2} \mathrm{O}_{5}$ with a decrease in the mass percentages of $\mathrm{C}_{\text {org }}$ and $\mathrm{CO}_{2}$ are observed. This due to a reduction of free carbonates and other impurities, these results contribute to improve the quality of WRP with an increase in solubility and chemical reactivity [10-15].

The ICP-AES analysis of some control constituents along the phosphate upgrading process proves that our sample is a 
carbonated phosphate which is quite lacked of magnesium, silica and metals oxides, whereas pyrite is totally absent (see Table 4).

Table 4. Chemical compositions of phosphates RP and WRP determined by ICP - AES

\begin{tabular}{ccc}
\hline $\begin{array}{c}\text { Chemical } \\
\text { compositions }\end{array}$ & RP $(\%)$ & WRP (\%) \\
\hline $\mathrm{P}_{2} \mathrm{O}_{5}$ & 31.00 & 31.70 \\
$\mathrm{CaO}$ & 49.60 & 50.85 \\
$\mathrm{~F}^{-}$ & 3.40 & 3.14 \\
$\mathrm{CO}_{2}$ & 6.50 & 5.87 \\
$\mathrm{SiO}_{2}$ & 1.38 & 1.20 \\
$\mathrm{H}_{2} \mathrm{O}$ & 4.86 & 4.14 \\
$\mathrm{Al}_{2} \mathrm{O}_{3}$ & 0.42 & 0.38 \\
$\mathrm{~K}_{2} \mathrm{O}$ & 0.07 & 0.12 \\
$\mathrm{MgO}$ & 0.65 & 0.5 \\
$\mathrm{Na}_{2} \mathrm{O}$ & 0.60 & 0.63 \\
$\mathrm{SO}$ & 1.52 & 1.47 \\
$\mathrm{Cd}(\mathrm{ppm})$ & 16.21 & 12.20 \\
$\mathrm{CaO} / \mathrm{P}_{2} \mathrm{O}_{5}$ & 1.6 & 1.6 \\
\hline ppm & Part per million
\end{tabular}

Our analysis results by ICP - AES show that RP and WRP contain a minor quantity of metals which does not exceed the standards [29-32]. This is expected because the content of metallic pollutants is directly linked to organic matter [26, 27, 29-32]. These analyzes also confirm the improvement in the quality of WRP following the reduction of impurities. For this, the thermal behavior and the stability of these metals will not be taken into account within our study.

\subsubsection{Mineralogical analysis}

Thermal analysis. To study the thermal behavior of phosphate and predict the necessary conditions for calcination, the thermal analyzes by differential thermal analysis (DTA) coupled with the thermogravimetric analysis (TGA), of RP and WRP were performed under airflow from the ambient temperature until $1000^{\circ} \mathrm{C}$ with a warming speed of $10^{\circ} \mathrm{C} /$ minute. Three successive mass losses have been highlighted [24]. The curves DTA-TGA of the phosphates studied (RP and WRP) are indicated in Figure 1.

The thermal analysis of DTA-TGA shows that both phosphates RP and WRP have similar thermal behavior but with lower peaks for WRP. This is due to the degradation of free carbonates, organic matter and the decrease in the level of physisorbed water. This weakness is indicated through the three main mass losses:

The $1^{\text {st }}$ mass loss is due to the dehydration represented by an endothermic peak observed around $80^{\circ} \mathrm{C}$. This peak is primarily attributed to the evaporation of the absorption water (moisture). The crystalline structure of apatite is not modified within this step;

The $2^{\text {nd }}$ mass loss starts around $200^{\circ} \mathrm{C}$ and spreads up to $550^{\circ} \mathrm{C}$. This mass loss results simultaneously from the superposition of an endothermic reaction (departure of structural water) and an exothermic reaction (combustion of organic matter);

The $3^{\text {rd }}$ mass loss launches at $550{ }^{\circ} \mathrm{C}$ and is due, to the continuity of the field of low exothermicity and, also, to the combustion of the residual organic matter and the high endothermicity domain. This is reflected in the decomposition of carbonates (calcite $\left(\mathrm{CaCO}_{3}\right)$ and dolomite $\left(\mathrm{CaMg}\left(\mathrm{CO}_{3}\right)_{2}\right)$ ) with a release of $\mathrm{CO}_{2}$. Thus, we remark a sharp increase concerns the speed of the loss of mass between 700 and $900^{\circ} \mathrm{C}$ which is assigned to the increase in the kinetics of the thermal decomposition of calcite. After that, we notice a uniform exothermicity which is due to recrystallization phenomena and sintering. At $1000^{\circ} \mathrm{C}$ the overall mass loss reaches the order of 9.2\% for RP and $8.6 \%$ for WRP. Therefore, a prewash of phosphate followed by calcination will reduce the consumption of fuels during calcination and the reagents during attack of phosphate.

Characterization by X-ray diffraction (XRD). The X-ray diffraction using the diffractometer XPRT MPD Panalytical Philips, with copper anticathode $\left(\lambda_{\mathrm{CuK}_{\alpha}}=1.5405 \mathrm{~nm}\right)$ at the ambient temperature, was used to identify crystalline phases of RP and WRP. As indicated in Figure 2.

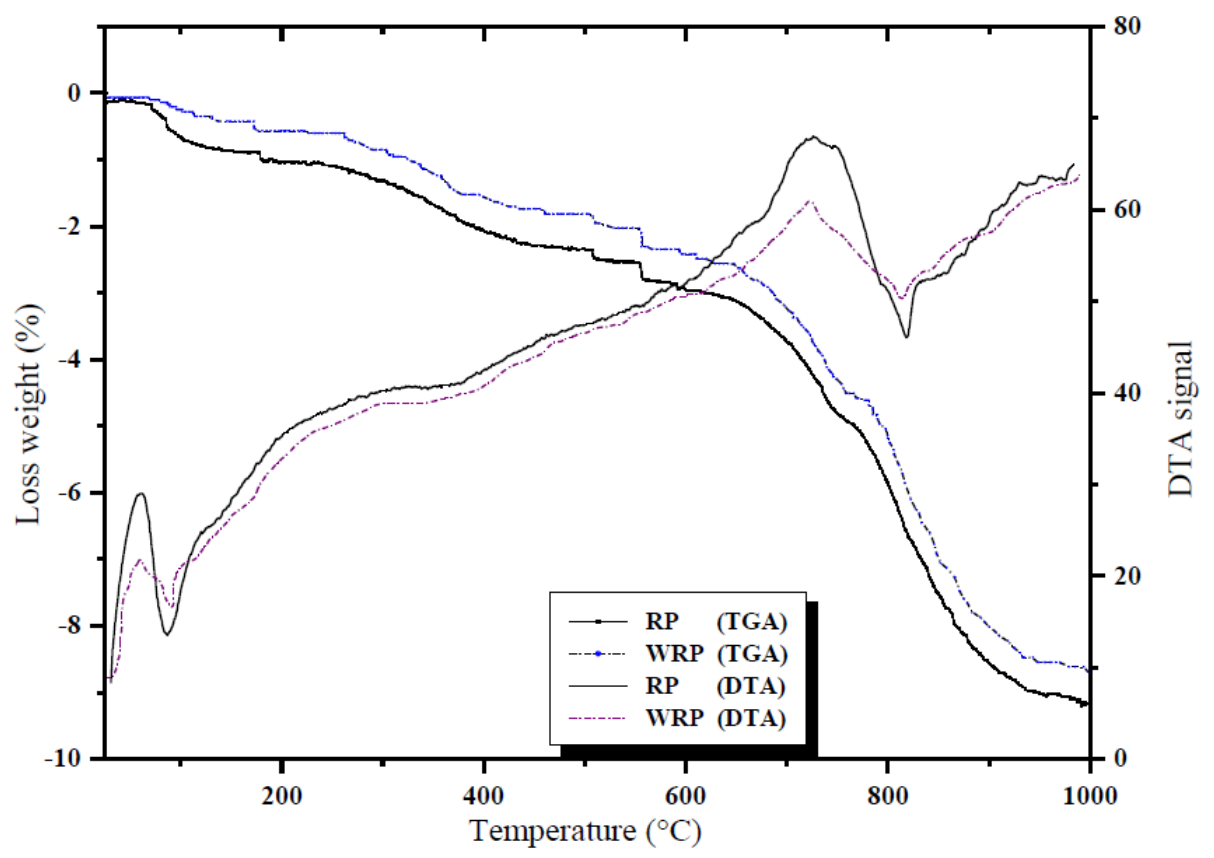

Figure 1. Curves DTA-TGA of the phosphates samples RP and WRP 

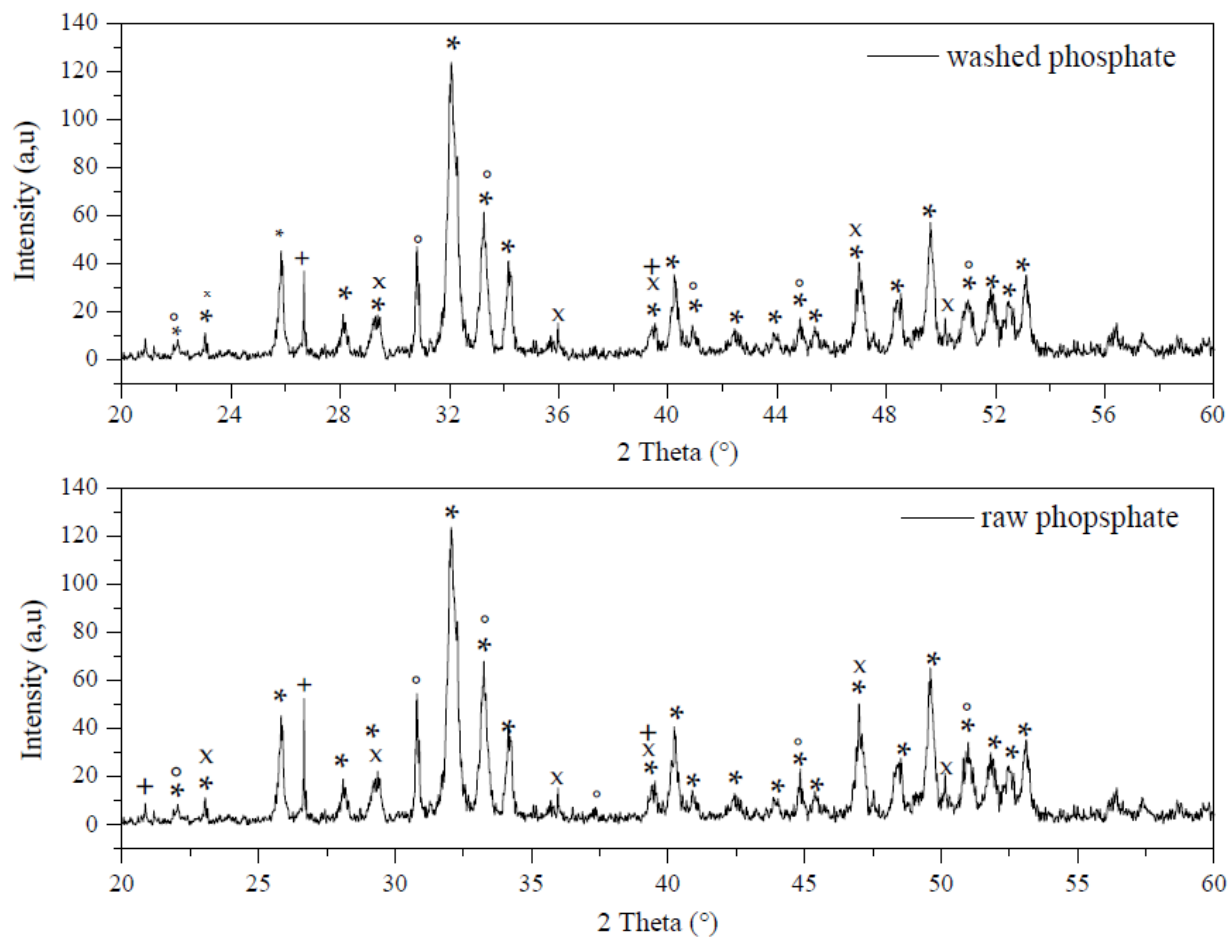

Figure 2. RX Diffractograms of RP and WRP Samples (*: Fluorapatite; +: Quartz; x: Calcite; ${ }^{\circ}$ : Dolomite)

The diffractogram reveals the presence of the following phases: Fluorapatite $\mathrm{Ca}_{10}\left(\mathrm{PO}_{4}\right)_{6} \mathrm{~F}_{2}\left(2 \theta: 32.2^{\circ} ; 49.8^{\circ} ; 25.8^{\circ}\right.$; $\left.34.33^{\circ} ; 53^{\circ} ; 51.8^{\circ} ; 48.4^{\circ} ; 49.6^{\circ} ; 28.2^{\circ} ; 52.2^{\circ}\right)$, quartz $\mathrm{SiO}_{2}(2 \theta$ : $26.587^{\circ} ; 50.1^{\circ} ; 20.885^{\circ}$ ) and carbonates that are in the form of dolomite $\mathrm{CaMg}\left(\mathrm{CO}_{3}\right)_{2}\left(2 \theta: 30.9^{\circ} ; 37.1^{\circ}\right)$ and calcite $\mathrm{CaCO}_{3}$ $\left(2 \theta: 36.041^{\circ}\right)$ (Figure 2). It appears that the recorded phases of
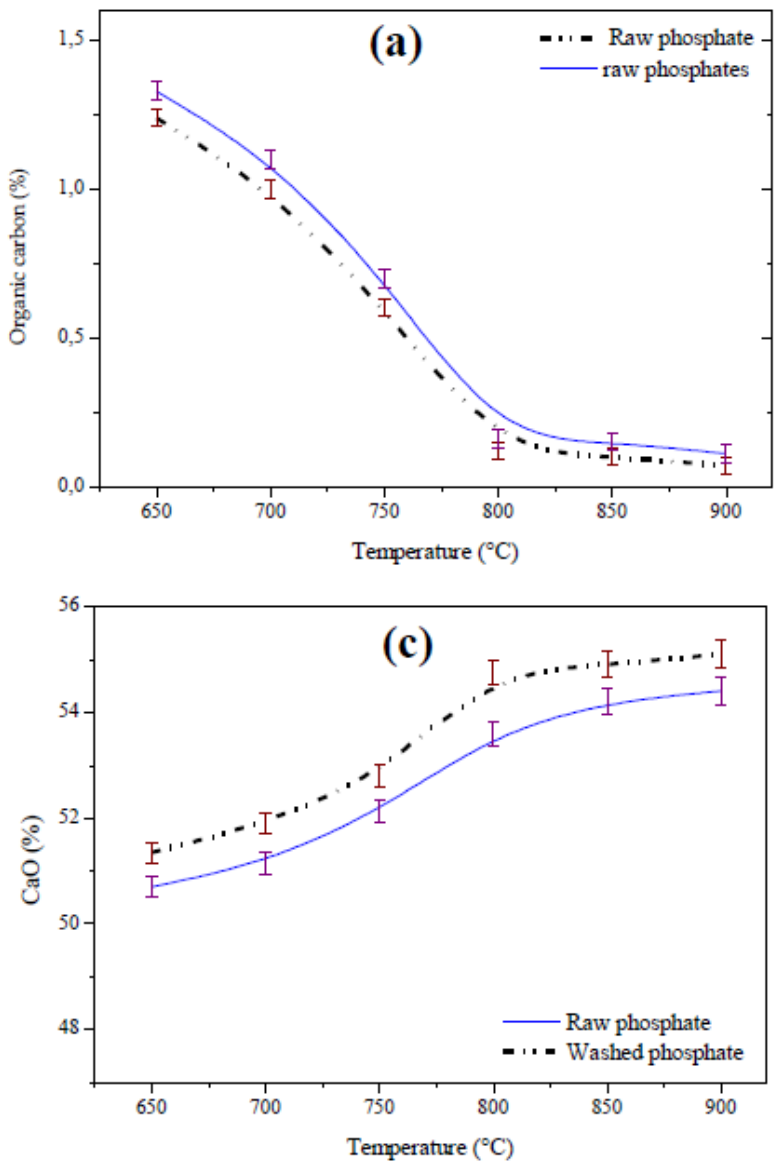

dolomite, calcite and quartz are due to their exogangue nature, whereas the interferences of these phases with fluorapatite are due to their endogenous nature. These latter overlaps are substantially reduced by washing, with an improvement in the resolution of X-ray diffraction peaks. This reflects some degree of crystallinity of WRP phosphate.
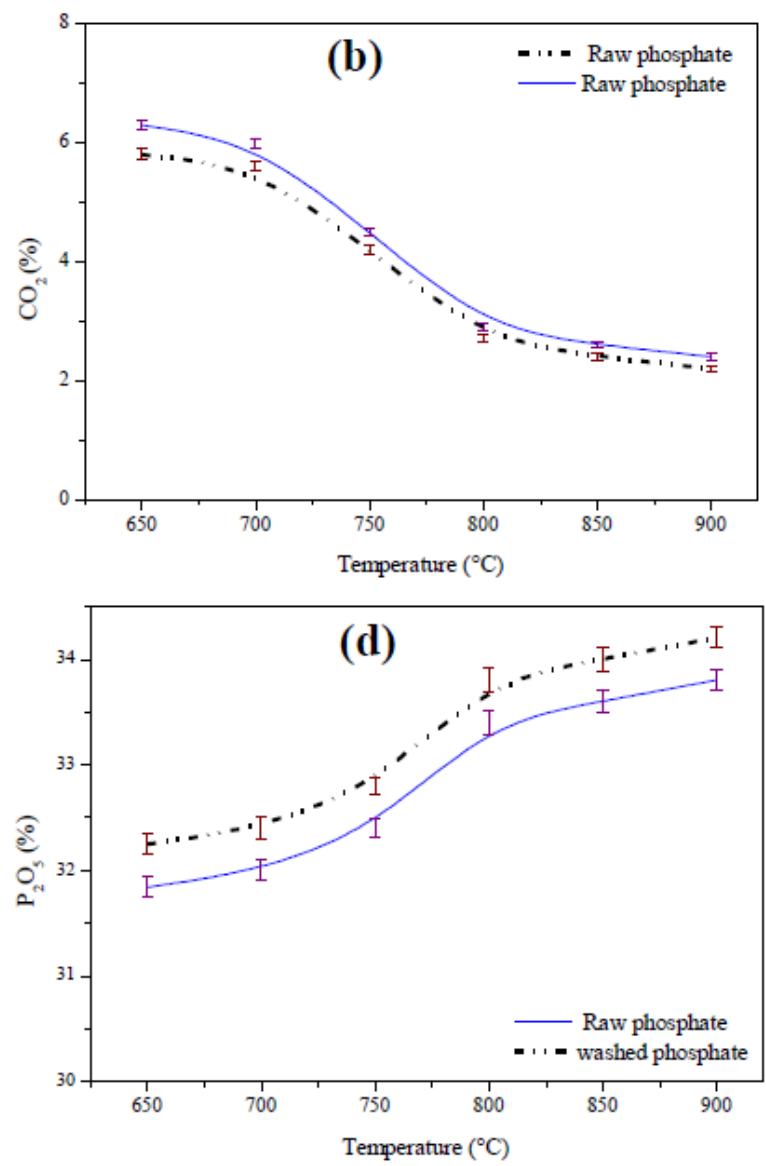

Figure 3. Variation of $\mathrm{C}_{\text {org }}, \mathrm{CO}_{2}, \mathrm{P}_{2} \mathrm{O}_{5}$ and $\mathrm{CaO}$ of the $\mathrm{RP}$ and WRP as a function of temperature for a calcination time of $30 \mathrm{~min}$ 

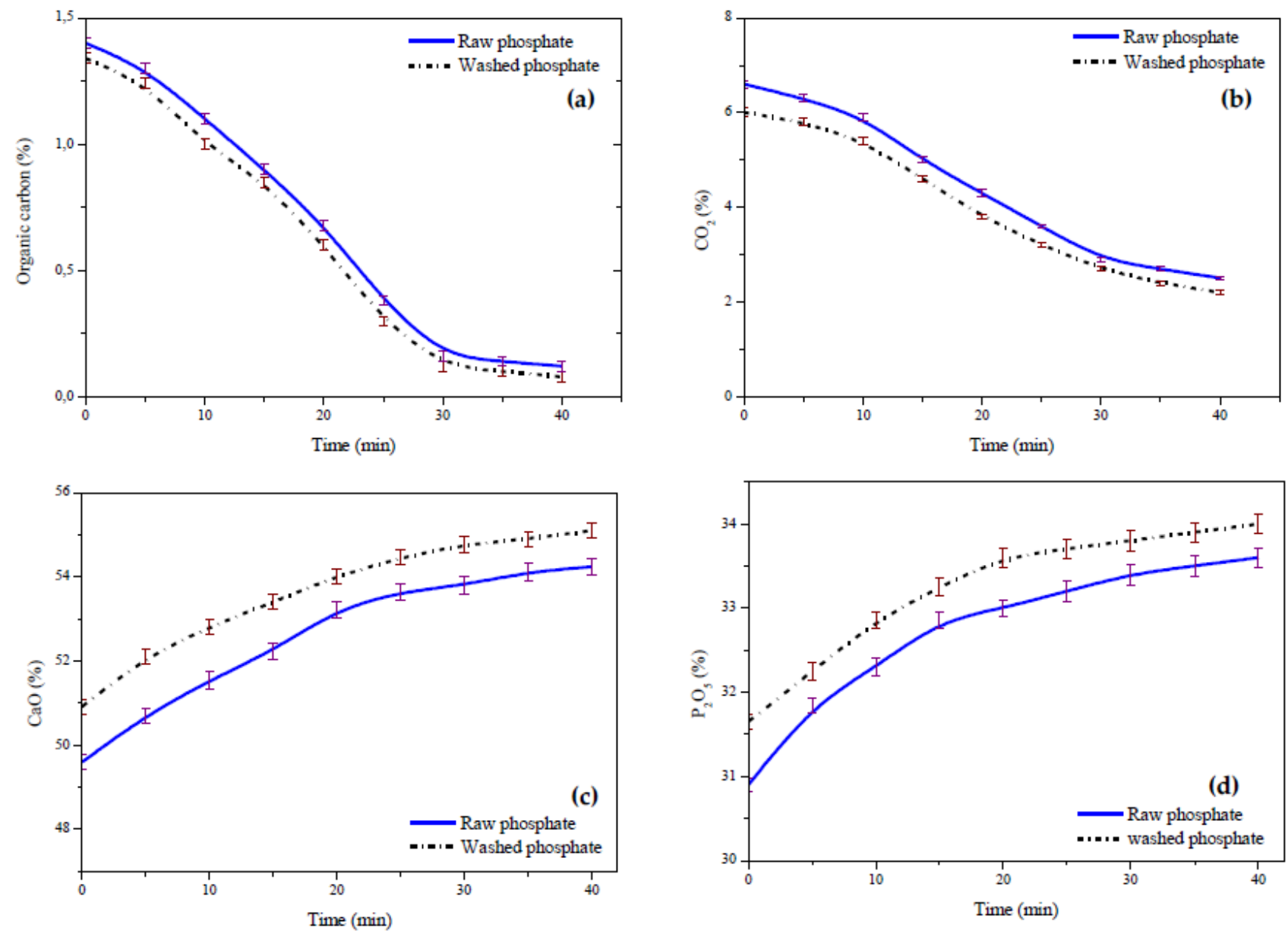

Figure 4. Variation of $\mathrm{C}_{\mathrm{org}}, \mathrm{CO}_{2}, \mathrm{CaO}$ and $\mathrm{P}_{2} \mathrm{O}_{5}$ of the $\mathrm{RP}$ and $\mathrm{WRP}$ as a function of the times at $800^{\circ} \mathrm{C}$

\section{THERMAL BEHAVIOR OF THE MAIN CONTROL CONSTITUENTS}

To determine the calcination conditions, we examined the evolution of the mass percentages of the main constituents as a function of time and temperature. For this, two classified samples of RP and WRP, of $200 \mathrm{~g}$, are placed each time inside a cylindrical stainless-steel container. Our experimental procedure is as follows [4, 24]:

Protocol "1": Study of the calcination temperature effect by introducing, each time, two samples (RP and WRP) in an adjustable electric oven at different temperatures $(650,700$, $750,800,850$, and $900^{\circ} \mathrm{C}$ ) during 30 minutes.

Protocol "2": Study of the calcination residence time effect by introducing, each time, two samples (RP and WRP) in the adjustable electric oven at a temperature of $800^{\circ} \mathrm{C}$ at different residence times $(5 ; 10 ; 15 ; 20 ; 25,30,35$ and $40 \mathrm{~min})$.

Before performing any analysis, the calcined products are first cooled down under the atmospheric pressure to the ambient temperature. Afterwards, they are submitted to extinction by air injection and sieved to eliminate the adsorbed volatile matter and the granulometric fraction below $40 \mu \mathrm{m}$, poor in phosphorus $[25,28]$. Our results of chemical analysis described through protocols "1" and "2" are shown in Figures 3 and 4.

Figure 3 show, a decrease in the organic carbon content and the release of carbon dioxide of RP and WRP compared to its initial concentrations ( 1.4 and $6.6 \%$ for RP and 1.34 and $6.0 \%$ for WRP) as a function of time and temperature. At $800^{\circ} \mathrm{C}$ and
30 minutes, the mass percentages of $\mathrm{C}_{\text {org }}$ and $\mathrm{CO}_{2}$ reaches minimum values of 0.16 and $3.1 \%$ for RP and 0.12 and $3.0 \%$ for WRP, from which these percentages remain almost stationary. Consequently, the respective mass percentages in $\mathrm{P}_{2} \mathrm{O}_{5}$ and $\mathrm{CaO}$ vary, respectively in the same way, as a function of time and temperature (Figures 3 and 4 ). At $800^{\circ} \mathrm{C}$ and 30 minutes, these mass percentages reach 33.4 and $53.8 \%$ for RP and 33.8 and $54 \%$ for WRP.

The chemical compositions of Bouchane phosphate before and after heat treatment are presented in Tables 5 and 6; Table 6 summarizes the results of the chemical analysis of RP and WRP calcined at $800^{\circ} \mathrm{C}$ during 30 minutes.

Table 5. Medium chemical compositions of phosphates RP, CRP, WRP and RPWC

\begin{tabular}{ccccc}
\hline Elements & $\begin{array}{c}\text { \% mass } \\
\text { of RP }\end{array}$ & $\begin{array}{c}\text { \% mass } \\
\text { of CRP }\end{array}$ & $\begin{array}{c}\text { \% mass } \\
\text { of WRP }\end{array}$ & $\begin{array}{c}\text { \% mass } \\
\text { of RPWC }\end{array}$ \\
\hline $\mathrm{P}_{2} \mathrm{O}_{5}$ & $30.90 \pm$ & $33.0 \pm$ & $31.65 \pm$ & $33.80 \pm$ \\
& 0.08 & 0.08 & 0.08 & 0.08 \\
$\mathrm{CaO}$ & $49.60 \pm$ & $53.80 \pm$ & $50.72 \pm$ & $54.76 \pm$ \\
& 0.18 & 0.20 & 0.19 & 0.20 \\
$\mathrm{CO}_{2}$ & $6.60 \pm$ & $2.90 \pm$ & $6.0 \pm$ & $2.70 \pm$ \\
& 0.08 & 0.06 & 0.08 & 0.06 \\
$\mathrm{C}_{\text {org }}$ & $1.40 \pm$ & $0.16 \pm$ & $1.34 \pm$ & $0.12 \pm$ \\
& 0.02 & 0.01 & 0.02 & 0.01 \\
$\mathrm{H}_{2} \mathrm{O}$ & $4.85 \pm$ & $2.50 \pm$ & $4.20 \pm$ & $2.40 \pm$ \\
& 0.01 & 0.01 & 0.01 & 0.01 \\
$\mathrm{Other}$ & $6.65 \pm$ & $7.24 \pm$ & $6.09 \pm$ & $6.22 \pm$ \\
& 0.52 & 0.50 & 0.45 & 0.46 \\
$\mathrm{CaO} / \mathrm{P}_{2} \mathrm{O}_{5}$ & 1.6 & 1.61 & 1.6 & 1.62 \\
\hline
\end{tabular}


Table 6. Chemical compositions of phosphates RP, CRP, WRP and RPWC determined by ICP - AES

\begin{tabular}{ccccc}
\hline $\begin{array}{c}\text { Chemical } \\
\text { compositions } \\
\text { of phosphates }\end{array}$ & $\begin{array}{c}\mathbf{R P} \\
(\boldsymbol{\%})\end{array}$ & $\begin{array}{c}\text { CRP at } \\
\mathbf{8 0 0}^{\circ} \mathbf{C} \\
(\%)\end{array}$ & $\begin{array}{c}\text { WRP } \\
(\%)\end{array}$ & $\begin{array}{c}\text { RPWC } \\
\text { at } \mathbf{8 0 0}^{\circ} \mathbf{C} \\
(\%)\end{array}$ \\
\hline $\mathrm{P}_{2} \mathrm{O}_{5}$ & 31.00 & 33.80 & 31.70 & 33.95 \\
$\mathrm{CaO}$ & 49.60 & 54.40 & 50.85 & 55.00 \\
$\mathrm{~F}^{-}$ & 3.40 & 3.30 & 3.14 & 3.00 \\
$\mathrm{CO}_{2}$ & 6.50 & 2.80 & 5.87 & 2.60 \\
$\mathrm{SiO}_{2}$ & 1.38 & 1.30 & 1.20 & 1.22 \\
$\mathrm{H}_{2} \mathrm{O}$ & 4.86 & 1.50 & 4.14 & 1.40 \\
$\mathrm{Al}_{2} \mathrm{O}_{3}$ & 0.42 & 0.31 & 0.38 & 0.30 \\
$\mathrm{~K}_{2} \mathrm{O}$ & 0.07 & 0.08 & 0.12 & 0.14 \\
$\mathrm{MgO}^{\mathrm{Na}}$ & 0.65 & 0.70 & 0.50 & 0.54 \\
$\mathrm{SO}_{3} \mathrm{O}$ & 0.60 & 0.50 & 0.63 & 0.52 \\
$\mathrm{Cd}_{2}(\mathrm{ppm})$ & 1.52 & 1.30 & 1.47 & 1.28 \\
$\mathrm{CaO} / \mathrm{P}_{2} \mathrm{O}_{5}$ & 16.21 & 16.60 & 12.20 & 12.50 \\
& 1.6 & 1.61 & 1.6 & 1.62 \\
\hline
\end{tabular}

As a result, at $800^{\circ} \mathrm{C}$ and after a residence time of $30 \mathrm{~min}$, the contents of $\mathrm{C}_{\text {org }}, \mathrm{CO}_{2}, \mathrm{CaO}$ and $\mathrm{P}_{2} \mathrm{O}_{5}$ vary slightly for the two calcined phosphates RP and WRP. From these conditions, the products obtained CRP and RPWC remain in alignment with the standards of use but with better quality for RPWC.

\section{BEHAVIOR OF ORGANIC MATTER AND CARBONATES OF CRP AND RPWC}

We have concluded that the calcination of RP and WRP requires a temperature of $800^{\circ} \mathrm{C}$ and a retention time of 30 minutes. However, the enrichment is never complete, as will be confirmed by the study of the thermal behavior of the samples calcined phosphates using a differential thermal analysis coupled to thermogravimetric analysis and X-ray diffraction; analysis by DTA-TGA, of RP and WRP are shows in Figure 5.

Figure 6 demonstrates the existence of three successive mass losses associated with different temperature ranges:

$1^{\text {st }}$ loss of mass "Dehydration": It is an endothermic peak of low amplitude initially attributed to the moisture linked to the adsorption phenomena, resulting from the hygroscopic equilibrium. It is observed at temperatures ranging between the ambient temperatures up to $100^{\circ} \mathrm{C}$ with a summit at around $80^{\circ} \mathrm{C}$;

$2^{\text {nd }}$ loss of mass: It is an endothermic peak that starts around $400^{\circ} \mathrm{C}$ due to the dehydration of the structural water and roasting of the remaining organic matter after calcination. We note here a compensation of the exothermic reaction by endothermicity which decreases the peaks of CRP and RPWC;

$3^{\text {rd }}$ loss of mass: It is launched at $750^{\circ} \mathrm{C}$ and is due to the decomposition of carbonates (calcite $\left(\mathrm{CaCO}_{3}\right)$ and dolomite $\left.\left(\mathrm{CaMg}\left(\mathrm{CO}_{3}\right)_{2}\right)\right)$ remaining in CRP and RPWC with release of $\mathrm{CO}_{2}$. Thermal analysis of the behavior of organic compounds and carbonates affirms that the total decomposition is effectively achieved only above $700^{\circ} \mathrm{C}$. We perceived that the loss of mass of the calcined phosphate, under the conditions of $800^{\circ} \mathrm{C}$ and 30 minutes of detainment, is of the order of $3.4 \%$ for CRP and $3.1 \%$ for RPWC.

The CRP and RPWC diffractograms reveal the presence of the following phases: fluorapatite $\mathrm{Ca}_{10}\left(\mathrm{PO}_{4}\right)_{6} \mathrm{~F}_{2}$, quartz, calcite and dolomite are presented in Figure 6. The carbonates exist in either endogangue or exogangue form. We note that the interferences between these compounds are removed during the calcination of RP and WRP. This disappearance of the phases is attributed to the decomposition of carbonates and the transformation of quartz into amorphous calcium silicate [4, $30,32,33]$.

These diffractograms show that the two samples are composed of phases with different intensities. The X-ray diffraction lines are refined and become resolved and less intense for RPWC, thus the width at half height and the noise of the bottom are lower with an improvement of the crystalline quality. This result in a better decarbonization of RPWC compared to CRP. This improvement also depends on the mass percentages of the other remaining impurities [34]. It is noted that this reduction has a positive effect on the consumption of reagents during the transformation of phosphate into phosphoric acid.

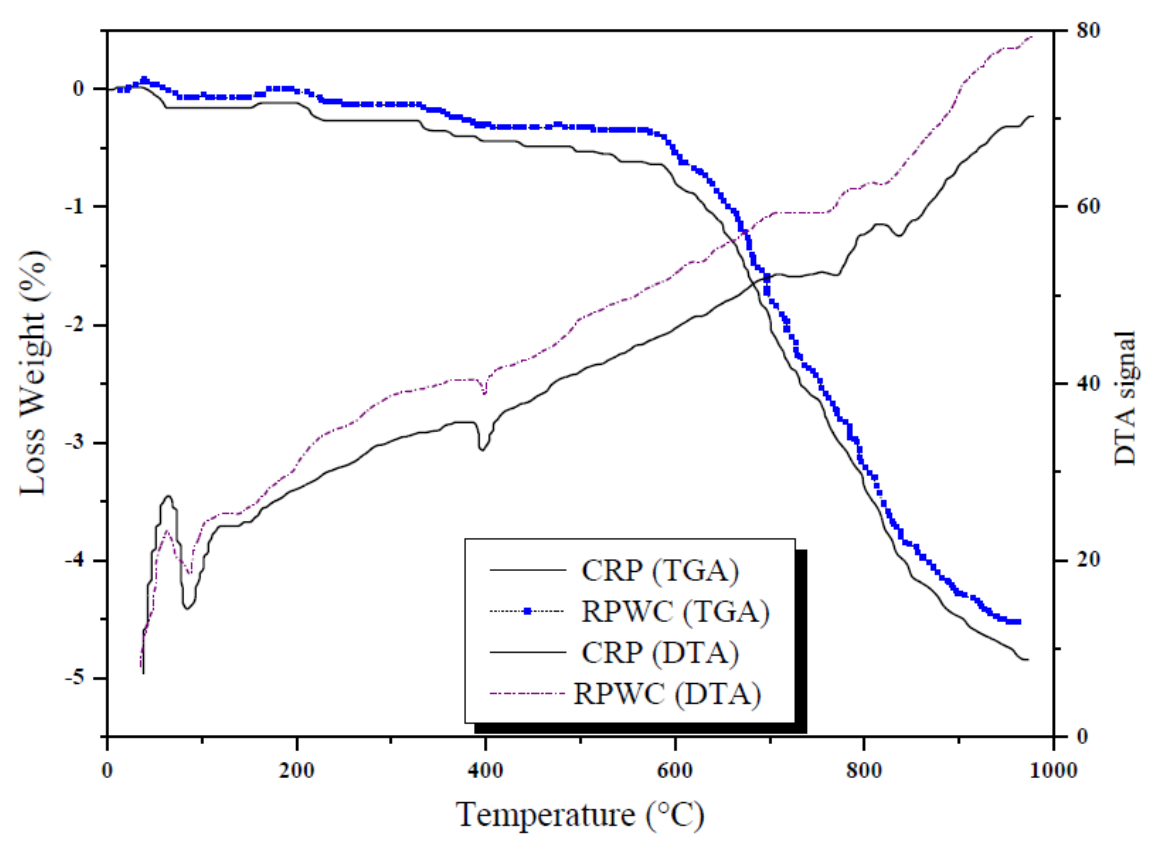

Figure 5. DTA-TGA curve of phosphate samples CRP and RPWC 

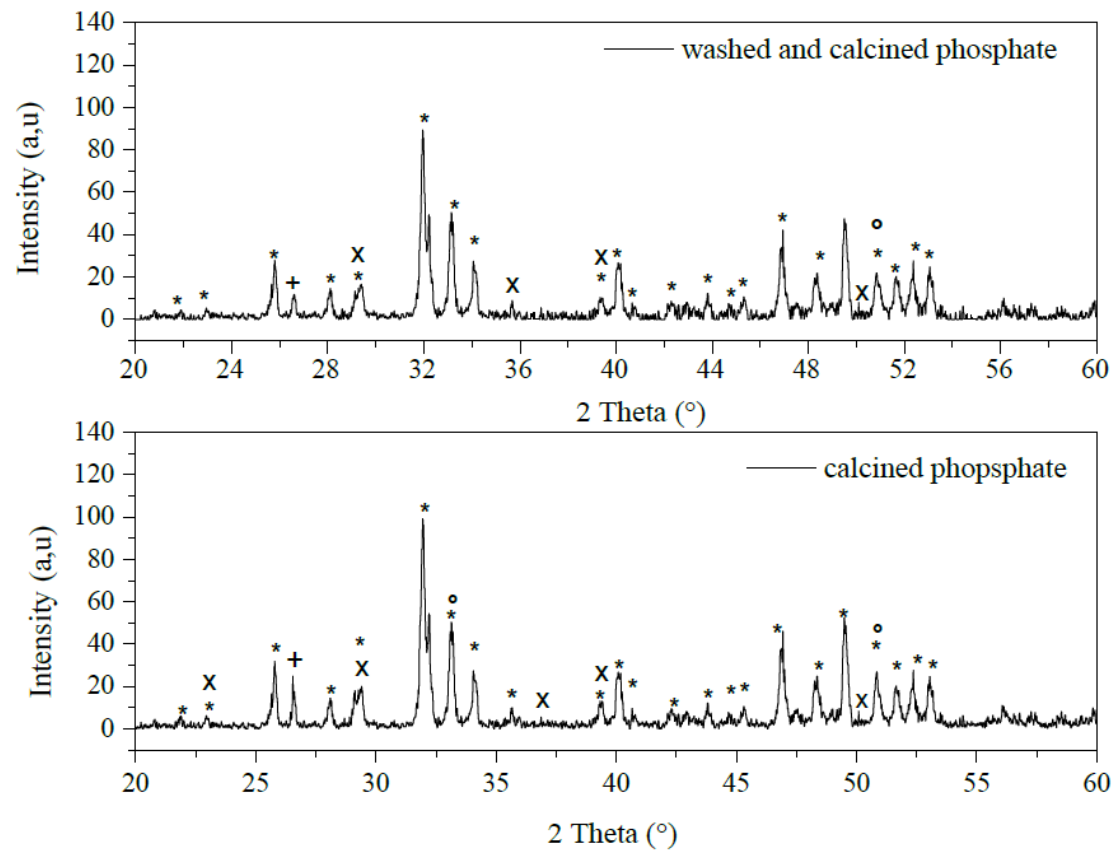

Figure 6. X-ray diffractograms of CRP and RPWC samples (*: Fluoroapatite, +: Quartz, x: Calcite and $\circ$ : Dolomite)

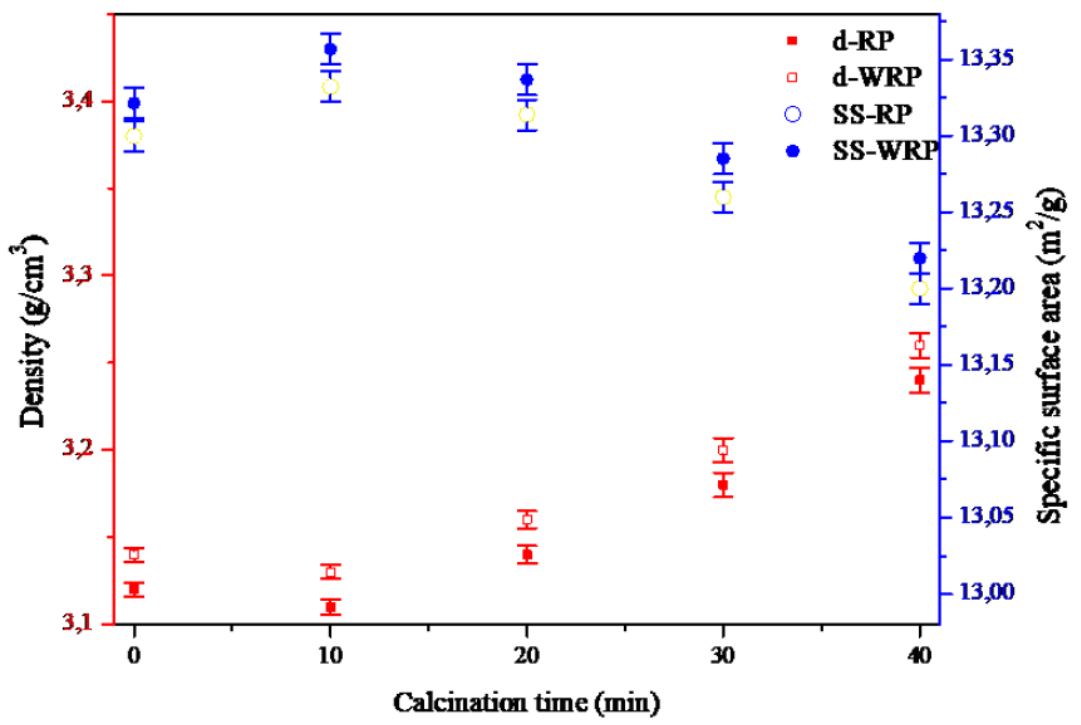

Figure 7. Evolution of the volumetric mass and the specific surface area of phosphate as a function of time at $800^{\circ} \mathrm{C}$ for RP and WRP

\section{BEHAVIOR OF THE MINERAL MATRIX OF RP AND WRP AS A FUNCTION OF TIME AT $800^{\circ} \mathrm{C}$}

During the calcination of phosphates, the combustion of organic matter and decomposition of carbonates induce a volume deformation. This leads to a change in the physical properties, such as the dimensions of the elementary mesh, the size of the crystals, the specific surface, the density, porosity and chemical reactivity that are interdependent [12]. To predict the behavior of these physical properties, we studied the variation of the specific surface and the volumetric mass during heat treatment. Figure 7 represents the evolution of these two parameters as a function of time at $800^{\circ} \mathrm{C}$. for $\mathrm{RP}$ and WRP.

It is found that, for a temperature of $800^{\circ} \mathrm{C}$ and residence time of calcination the $30 \mathrm{~min}$, the specific surface and the volumetric mass of the WRP remain important compared to those of the RP. This is expressed by the elimination of fine grains containing the carbonates by prewashing; this elimination promotes the kinetics of calcination by causing destruction of the pores, following the ventilation of volatile gases which will be very rapid. This results in an increase in chemical reactivity and solubility, and therefore the quality of WRP [2].

\section{CONCLUSIONS}

Our study highlights a strong relation between the evolution of the mineralogical phases, the granulometric distribution, specific surface, volumetric mass and the main control constituents as a function of time and temperature. We have demonstrated that the calcination at $800^{\circ} \mathrm{C}$ for 30 minutes of the two types of phosphates RP and WRP responds well to the 
market profiles and to the use requirements. Under these conditions, we noted a decrease in organic carbon from $11.4 \%$ to $8.57 \%$ and in carbon dioxide from $47 \%$ to $45.46 \%$ accompanied by an increase in the weight of $\mathrm{P}_{2} \mathrm{O}_{5}$ from $9.15 \%$ to $10.46 \%$ for RPWC. Furthermore, we also noticed, a decrease in the concentration of impurities without affecting the ratio $\mathrm{CaO} / \mathrm{P}_{2} \mathrm{O}_{5}$ which is around 1.6; an increase, of the chemical reactivity and solubility of RPWC compared to CRP, is also highlighted.

We concluded that the calcination after washing is better compared to the usual calcination of Bouchane phosphate ore, when it comes to quality, energy and environment.

\section{ACKNOWLEDGMENT}

This manuscript was subjected to a profound scrutiny performed by Mr. Mohammed SAISSI, An ELT teacher in Directorate of Safi-Morocco and a PhD student in department of English at the faculty of letters and human sciences in Mohammedia, University Hassan II, Casablanca, Morocco. Accordingly, we'd like to thank him for his fruitful contribution to release this paper.

\section{REFERENCES}

[1] Aissa, A., Abdeen, A., Abualreish, M. (2014) Qualitative and quantitative analysis of phosphate rock from Hazm Al-jalamid area, northern Saudi Arabia. International Journal of Basic and Applied Sciences, 3: 190-198. https://doi.org/10.14419/ijbas.v3i3.2755

[2] Ruan, X.F., He, D.S., Chi, R. (2019). Review on beneficiation techniques and reagents used for phosphate ores. Minerals, 9(4): 253 https://doi.org/10.3390/min9040253

[3] Mcclellan, G.H., Van Kauwenbergh, S.J. (1991) Mineralogical and chemical variation of francolites with geological time. Journal of the Geological Society, 148: 809-812. https://doi.org/10.1144/gsjgs.148.5.0809

[4] Ouardi, E.M., Chehouani, H., Mrani, I., Anoua, M., Noubhani, A. (2012). Optimization of the heat treatment of phosphate. Revue de Métallurgie, 109(6): 453-463. https://doi.org/10.1051/metal/2012041

[5] El Ouardi, E. (2013). Effect of temperature and residence time of calcination phosphate on the chemical reactivity: Application to the case of Bouchane phosphate (Morocco). International Journal of Innovation and Applied Studies, 4(2): 387-407.

[6] Xie, F., Zhang, J., Chen, J.Y., Wang, J.R., Wu, L. (2019). Research on enrichment of $\mathrm{P}_{2} \mathrm{O}_{5}$ from low grade carbonaceous phosphate ore via organic acid solution. Journal of Analytical Methods in Chemistry, 2019: 1-7. https://doi.org/10.1155/2019/9859580

[7] Shahram, S., Aisan, R., Armin, S. (2015). Beneficiation of low-grade phosphate deposits by a combination of calcination and shaking tables: Southwest Iran. Minerals, 5(3): 367-379. https://doi.org/10.3390/min5030367

[8] Elbendary, A., Aleksandrova, T., Nikolaeva, N. (2019). Influence of operating parameters on the flotation of the Khibiny Apatite-Nepheline Deposits. Journal of Materials Research and Technology, 8(6): 5080-8090. https://doi.org/10.1016/j.jmrt.2019.08.027

[9] Zafar, Z.I., Anwar, M.M., Pritchard, D.W. (1996)
Innovations in beneficiation technology for low grade phosphate rocks. Nutr. Cycl. Agroecosyst, 46: 135-151. https://doi.org/10.1007/BF00704313

[10] Abouzeid, A.Z.M. (2008). Physical and thermal treatment of phosphate ores-An overview. International Journal of Mineral Processing, 85(4): 59-84. https://doi.org/10.1016/j.minpro.2007.09.001

[11] Guo, F., Li, J. (2010). Separation strategies for Jordanian phosphate rock with siliceous and calcareous gangues. International Journal of Mineral Processing, 97(1-4): 7478. https://doi.org/10.1016/j.minpro.2010.08.006

[12] Straaten, P.V. (2002). Rocks for crops: Agro minerals of sub-Sahara Africa. ICRAF International Centre for Research in Agroforestry, 338: 7-24.

[13] Singh, V., Chakraborty, T., Tripathy, S.K. (2019). A review of low grade manganese ore upgradation processes. Mineral Processing and Extractive Metallurgy Review, $1-23$. https://doi.org/10.1080/08827508.2019.1634567

[14] Martins, M.A., Oliviera, L.S., Franca, A.S. (2001). Modeling and simulation of petroleum coke calcination in rotary kilns. Fuel, 80(11): 1611-1622. https://doi.org/10.1016/S0016-2361(01)00032-1

[15] Jordens, A., Cheng, Y.P., Waters, K.E. (2013). A review of the beneficiation of rare earth element bearing minerals. Minerals Engineering, 41: 97-114. https://doi.org/10.1016/j.mineng.2012.10.017

[16] Shariati, S., Ramadi, A., Salsani, A. (2015). Beneficiation of low-grade phosphate deposits by a combination of calcination and shaking tables: Southwest Iran. Minerals, 5(3): 367-379. https://doi.org/10.3390/min5030367

[17] Ahmed, S.M., Rizk, A.M.E. (1999). Effect of particle size on dilute slurry erosion. Bulletin of the Faculty of Engineering, Assiut University, 27(1): 231-241.

[18] Gu, Z. (2002). Fine particle flotation for Florida dolomitic phosphate pebbles. Master's Thesis, College of Engineering and Mineral Resources, West Virginia University, Morgantown, WV, USA.

[19] Onal, G., Bulut, G., Gul, A., Kangal, O., Perek, K.T., Arslan, F. (2005). Flotation of Aladag oxide lead-zinc ores. Minerals Engineering, 18(2): 279-282. https://doi.org/10.1016/j.mineng.2004.10.018

[20] Negm, A.A., Abouzeid, A.Z.M. (2008). Utilization of solid wastes from phosphate processing plants. Physicochem. Probl. Miner. Process, 42(2008): 5-16.

[21] EL-Gillani, D.A., Abouzeid, A.Z.M. (1993). Flotation of carbonates from phosphate ores in acidic media. International Journal of Mineral Processing, 38(3-4): 235-256. https://doi.org/10.1016/0301-7516(93)90077$\mathrm{N}$

[22] Zafar, Z.I., Anwar, M.M., Pritchard, D.W.A. (1996). A new route for the beneficiation of low grade calcareous phosphate rocks. Fertilizer Research, 44: 133-142. https://doi.org/10.1007/BF00750803

[23] Khoshjavan, S., Rezai, B. (2011). Beneficiation of refractory rock phosphate by calcination and flotation. Miner. Metall. Process, 28: 187-192. https://doi.org/10.1007/BF03402450

[24] El Ouardi, M., Saadi, L., Waqif, M., Chehouani, H., Mrani, I., Anoua, M., Noubhani, A. (2010). Characterization of the bouchane phosphate (Morocco) and study of the evolution of the main control elements of its calcination. Physical and Chemical News, 54: 68- 
75.

[25] Bakkali, S. (2006). Application du filtrage spatial à l'analyse des contours des zones anomales de «dérangements» des séries phosphatées de Sidi Chennane, Maroc. Afrique Science, 2(1): 116-13. https://doi.org/10.4314/afsci.v2i1.61143

[26] Bilali, L., Aouad, A., EL Harfi, K., Benchanâa, M., Mokhlisse, A. (2002). Pyrolysis of the Moroccan (Youssoufia) rock phosphate. Journal of Analytical and Applied Pyrolysis, 65(2): 221-237. https://doi.org/10.1016/S0165-2370(02)00002-5

[27] Vosteen, H.D., Schellschmidt, R. (2003). Influence of temperature on thermal conductivity, thermal capacity and thermal diffusivity for different types of rock. Physics and Chemistry of the Earth, Parts A/B/C, 28(911): 499-509. https://doi.org/10.1016/S14747065(03)00069-X

[28] Hadji, I., Bouzekri, M., Malek, N. (2015). Influence de traitement thermique sur les propriétés chimique et minéralogique du minerai de phosphate beige de Kef Essennoun. Thesis, université Abderahmane Mira Bejaia.

[29] Tack, F.M.G., Singh, S.P., Verloo, M.G. (1999). Leaching behaviour of $\mathrm{Cd}, \mathrm{Cu}, \mathrm{Pb}$ and $\mathrm{Zn}$ in surface soils derived from dredged sediments. Environmental Pollution, 106(1):
https://doi.org/10.1016/S0269-7491(99)00053-6

[30] Aouad, A., Benchanâa, M., Mokhlisse, A., Arafan, A. (2002). Study of thermal behaviour of organic matter from natural phosphates (Youssoufia - Morocco). Journal of Thermal Analysis and Calorimetry, 70: 593603. https://doi.org/10.1023/A:1021601329760

[31] Shu, X., Xu, X., Fan, H., Wang, S., Yan, D. (2002). Application of TG - DTG analysis and centrifugal separation in the investigation of less combustible constituents in coals. Thermochimica Acta, 381(1): 7381. https://doi.org/10.1016/S0040-6031(01)00647-5

[32] Mouflih, M., Aklil, A., Sebti, S. (2005). Removal of lead from aqueous solutions by activated phosphate. Journal of Hazardous Materials, 119(1-3): 183-188. https://doi.org/10.1016/j.jhazmat.2004.12.005

[33] Aouad, A., Benchanâa, M., Mokhlisse, A., Ounas, A. (2004). Thermal analysis of Moroccan phosphates "Youssoufia" in an oxidative atmosphere by TG and DSC. Journal of Thermal Analysis and Calorimetry, 75: 887-900. https://doi.org/10.1023/B:JTAN.0000027183.13313.c0

[34] Sandrine, L. (2003). Synthesis and thermal behavior (stability and sintering) of ceric or yttric rare earth phosphates. Ph.D. Thesis. Sciences and technologies Faculty, University of Limoges, France. 